\title{
OUTCOME OF 337 INTRACRANIAL ANEURYSMS PATIENTS OPERATED IN A PUBLIC HOSPITAL
}

\author{
JOSÉ CARLOS LYNCH*, RICARDO ANDRADE**, CELESTINO PEREIRA***, \\ MILTON SOUZA NETO****, ROQUE DOMINGUEZ****
}

\begin{abstract}
Many recent series of surgery for intracranial aneurysms have been based on experience of developed countries with great resources and a state of art health care. The purpose of the current study is to correlate the outcome of patients operated for intracranial aneurysms. reported from intensive high technology neurosurgical centers with the results of low technology, environment, where we practice. Between January 1986 and December 1996, 337 patients with intracranial aneurysms were operated on at the Servidores do Estado Hospital. We retrospectively reviewed the medical and radiologic records and compared the outcome of this group with other series derived from developed countries. The overall mortality of this series was $6.9 \%$. Of the 313 good grades surgical patients, the mortality was $4.7 \%$ and the sucessfull results were obtained in $88.8 \%$ individuals. We conclude that patients harboring intracranial aneurysms can be satisfactory handled in less developed nations, if a meticulous intraoperative technique is employed, even though sophisticated technology and equipments are not available.
\end{abstract}

KEY WORDS: intracranial aneurysm, subarachnoid hemorrhage, microneurosurgery.

\section{Resultados da cirurgia de 337 pacientes portadores de aneurisma intracraniano operados em um hospital público}

RESUMO - Séries recentes que analisam os resultados da cirurgia de aneurismas intracranianianos são originadas de países com grande desenvolvimento médico e tecnológico. O objetivo do presente estudo é comparar os resultados dessas series com os resultados obtidos por um serviço de neurocirurgia de um hospital público (HSE) no Brasil. A mortalidade geral neste estudo foi de 6,9\%. Dos 313 bons candidatos cirurgicos, a mortalidade encontrada foi de $4,7 \%$. Neste grupo, $88,8 \%$ dos pacientes retornaram a sua vida prévia. Concluímos que pacientes com aneurismas intracranianos podem ser satisfatoriamente tratados em países menos desenvolvidos, se uma técnica cirurgica meticulosa for empregada, mesmo sem dispormos de tecnologia cara e sofisticada.

PALAVRAS-CHAVES: aneurisma intracraniano, hemorragia subaracnóidea, microcirurgia.

Great advancements have been seen in Neurosurgery. Among these, have been the introduction and development of instrumentation and microsurgical techniques for surgery of intracranial aneurysms. The advancement in techniques and technology in the last few years demands organization and great amount of fundings to replace equipments and in purchasing new technology. However, in countries where this is not the case, neurosurgeons have been made a great effort to optimize limited resources and a more selective approach may well be justified. Many recent series of surgery for intracranial aneurysms have been based on experience in developed countries with great resources and a state-of-art health care cil- $^{1-13}$.

Hospital dos Servidores do Estado (HSE) Department of Neurosurgery, Rio de Janeiro, Brazil: *Chairman; **Vice-Chairman; ***Assistant; ****Resident. This paper was partially presented at the 11 th International Congress of Neurological Surgery. Aceite: 27-maio-1998.

Dr. José Carlos Lynch - Av. das Américas 1155/510 - 22631-000 Rio de Janeiro RJ - Brasil. 
The intent of this study is to compare the outcome of patients operated for intracranial aneurysms reported from intensive high technology developed neurosurgical center with the results of low technology environment in which we practice.

\section{METHODS}

\section{Patients population}

During 11 year period (January 1986 - December 1996) 337 patients with a diagnosis of an intracranial aneurysm were operated in the Hospital Servidores do Estado (HSE). Data from each patient were collected retrospectively from their charts, operative notes and angiography. This information was recorded on a standard abstract sheet and stored in a computer for analysis. There were $214(63.7 \%)$ woman and $123(36.2 \%)$ men. Their ages ranged from 5 to 77 years (median age 45.4 years). The patient's condition at admission was classified according to scale of Hunt and Hess. The outcome were categorized as successful (full neurological recovery or minimal to moderate disability), unsuccessful (severe disability, a vegetative state and death). 313 patients (89.8\%) were in good condition (neurological grades I to III) and 35 (10.2\%) were in poor condition (grades IV and V) when operated on.

In $169(50 \%)$ individuals, the ruptured aneurysm arose from the internal carotid artery (ICA), including the ophthalmic, posterior communicating or anterior choroidal arteries and the bifurcation. In 75 (22.2\%) patients the aneurysm was located in the anterior communicating artery complex (ACOA). In 72 (21.3) individuals the aneurysm arose from the middle cerebral (MCA), and in 21 (6.2\%) patients from the vertebral basilar system (VBS). 38 aneurysms (11.4\%) were giant. Multiple aneurysm were found in $28.5 \%$ of the cases. Most of the patients in our series presented subarachnoid hemorrhage (SAH) (90.9\%).

\section{Management of cases}

All patients had bilateral carotid angiography and most of the patients had vertebral angiography as well. Computerized tomography had come into routine use in the evaluation of these patients during this period. Most of the patients were operated on 7 days or more following their last SAH. No antifibrinolytic agents were used. Steroids, and after 1991, venous or oral calcium antagonists were used routinely. Hypervolemic, hypertensive therapy was employed only after aneurysm clipping and development of cerebral vasospasm.

Transcranial doppler examination, transluminal ballon angioplasty, somatosensory evoked potential, as well as intraoperative angiography were not avaible in our institution during the period of this study.

\section{Surgical technics}

Most operations were performed by the senior author (JCL), using an OPML-1 model of the Zeiss operating microscope (Carl-ZEISS, New York, USA).

The patient is placed in a Mayfield-tree pin head holder and the surgical approach for supratentorial aneurysms is the standard pterional craniotomy. Employing meticulous micro surgical techniques, the Sylvian, the carotid and the suprachiasmatic cisterns are widely open to expose the aneurysms. The aneurysms were then obliterated by clipping. Hypotensive anesthesia was never used in these series as well as lumbar cerebro-spinal fluid drainage.

The anesthetic monitoring consisted of ECG, digital oximetry, capnography, and intrarterial blood pressure. Close nursing observation of the patient in post operative period is undertaken in a general intensive care unit for a variable period of time, most often overnight. After that, the patient is transferred to neurosurgical ward until hospital discharge.

\section{RESULTS}

The overall mortality of this series was $6.9 \%$ (23 patients). The successful results for all patients was $84.2 \%$ (284 patients) and unsuccessful $15.7 \%$ (53 patients).

Considering only the 313 good grades surgical patients (Hunt and Hess grades I to III), the successful results were obtained in $88.8 \%$ (278) patients with $11.1 \%$ (35 patients) in the unsuccessful category. The mortality in these group was $4.7 \%$ (15 patients).

\section{Method of treatment}

Neck clipping was the goal of all operations. Satisfactory clipping of the aneurysm was accomplished in $91.4 \%$ of the aneurysms. 
Proximal ligation or trapping of the aneurysm was performed only in 10 instances $(3.1 \%)$. Wrapping was chosen in 16 aneurysms (4.7\%).

In 26 patients $(7.7 \%)$, the aneurysm ruptured on surgical procedure: 18 during the neck dissection and 6 at the neck clipping.

In the 38 patients, temporary clipping were used, with the time varying from 2 to 50 minutes. In the last 5 years the aneurysm has been routinely decompressed after clipping, by incision or needle aspiration.

\section{DISCUSSION}

\section{Timing of operation}

At the moment there is a tendency in neurological community to proceed with definitive aneurysmal surgery as soon as logistically possible, at least in patients in good condition. However, the timing of aneurysm surgery remains controversial and currently there are no definitive data to support an universal policy of either early or late surgery ${ }^{1-6,8,10,11}$.

In this series most of patients were operated on 7 days or more following their last SAH and after the immediate effect of the SAH had passed.

\section{Method of treatment}

Surgical results in cases of ruptured cerebral aneurysm have improved with the introduction of the operative microscope.

In this series, the aneurysms were clipped in $91.4 \%$ of the cases. Artiola et al. ${ }^{14}$ clipped $87.9 \%$ of the aneurysms. Nornes and Wikeby ${ }^{7}$ reported $85 \%$ of successful clipping. Temporary clipping were used in 38 instances, the time varying from 2 to 50 minutes. Rupture during dissection or clipping occurred in 25 patients (7.4\%). Batjer and Samson ${ }^{15}$ and Yasargil ${ }^{13}$ reported similar pattern of intraoperative aneurysm rupture.

\section{Assessment of Outcome}

Several large series of patients submitted to early or late surgery after aneurysmal SAH have been published to date. All these series come from developed countries with great resources and state-of-art medical care ca, $2,4,6-11,13,16-20$.

The microsurgical era began with the paper of Krayenbühl et al. ${ }^{16}$ Excellent/good results were obtained in $83 \%$ of the entire series. There were no death in 112 grade I and II patients.

Nornes and Wikeby ${ }^{7}$ presented successful results in $80 \%$ of the good/excellent patients. Sundt et al. ${ }^{9}$ operated on 722 patients with intracranial aneurysm. They obtained excellent or good results in $87 \%$ of patients, in $13 \%$ the results were poor or the patient died. Ljungreen et al. ${ }^{18}$, operated on 105 patients in the acute stage. Of 95 grade 1 to III patients who were operated on, $76 \%$ recovered without neurological deficits and $4 \%$ died. The same group, in other similar study showed nearly corresponding results 5 .

Chyatte et al. ${ }^{2}$ analyzed 244 patients admitted at Mayo Clinic. Eighty-five patients underwent surgery between zero and 3 days following SAH , 83 patients between 4 to 9 days and in 50 individuals the surgery to secure the aneurysm was done 10 days or more after the SAH. Successful results were obtained in $80.2 \%$ of the patients operated in acute stage and $78.6 \%$ of the late surgery group. Ohman and Heiskanen ${ }^{8}$ obtained full neurological recovery or moderate disability in $83.4 \%$ of their good candidate patients. Krupp et al. ${ }^{4}$ have presented their results of 131 patients that underwent late operation. They achieved excellent/good patients outcome in $85 \%$ of their good grades post HSA patients.

More recently, Le Roux et al. ${ }^{17}$ studied 543 individuals admitted with SAH, during a 10-year period, utilizing state-of-art medical care, like as special neurosurgical intensive care with routine intracranial pressure, invasive hemodynamic monitoring, daily transcranial doppler examination, 
Table 1. Surgical outcome in good grade* subarachnoid patients.

\begin{tabular}{|c|c|c|c|c|}
\hline Authors & Year & Timing & $\begin{array}{c}\text { Successful } \\
\text { outcome } \\
\text { excellent/good }\end{array}$ & $\begin{array}{l}\text { Unsuccessful } \\
\text { outcome } \\
\text { poor/death }\end{array}$ \\
\hline Post et al. ${ }^{19}$ & 1977 & LS & 70.0 & 30.0 \\
\hline Nornes and Wikeby ${ }^{7}$ & 1979 & LS & 80.0 & 20.0 \\
\hline Adams et al. ${ }^{1}$ & 1981 & LS & 55.7 & 44.2 \\
\hline Sundt et al. ${ }^{9}$ & 1982 & LS & 87.0 & 13.0 \\
\hline Shephard ${ }^{20}$ & 1983 & ELS & 63.6 & 36.3 \\
\hline Yasargil $^{13}$ & 1984 & LS & 94.7 & 5.3 \\
\hline Ljungren et al. ${ }^{18}$ & 1985 & ES & 76.0 & 24.0 \\
\hline Chiatte et al. ${ }^{2}$ & 1988 & ELS & 77.5 & 22.4 \\
\hline Ohman and Heiskanen $^{8}$ & 1989 & ELS & 83.4 & 16.5 \\
\hline Miyaoka et al. ${ }^{6}$ & 1992 & LS & 80.2 & 19.8 \\
\hline Miyaoka et al. ${ }^{6}$ & 1992 & ES & 78.6 & 21.4 \\
\hline Krupp et al. ${ }^{4}$ & 1994 & LS & 85.0 & 15.0 \\
\hline Le Roux et al. ${ }^{17}$ & 1995 & ES & 86.6 & 13.4 \\
\hline Lynch et al. & 1996 & LS & 88.7 & 11.3 \\
\hline
\end{tabular}

ES, early surgery; LS, late surgery; ELS, early and late surgery.

*Good grade: Hunt \& Hess grades I to III.

early surgery and aggressive treatment of vasospasm. They present favourable outcome in $86.6 \%$ of the Hunt \& Hess grades I to $\mathrm{III}^{21}$. Yasargil ${ }^{13}$ reviewed his series of 1012 aneurysm patients operated upon. The great majority of the patients had late surgery. He claimed excellent/good results in $94.7 \%$ of this good grade patients (Table 1).

In this present series, 337 patients were operated upon for intracranial aneurysm. The overall surgical mortality was $6.9 \%$ (23 patients). Considering Hunt e Hess grades I to III ${ }^{21}$, there were 313 patients operated upon. Of these, $278(88.8 \%)$ achieved satisfactory outcome (they could return to their pre-morbid level, some with minor neurologic deficits). In the unsuccessful category, 35 patients $(11.3 \%)$ had poor outcome.

The majority of the operations, in this study, were performed after 7 days of SAH. These patients have survived the acute stages of SAH, the rebleedings in the early period of SAH and problems related to vasospasm. Also in this situation, the effects of acute hemorrhage had decreased, thus making the surgery easier to perform. These facts most probably improve our results when compared with series of patients who were operated on in acute stages of aneurysms SAH.

Ideally, the state-of-art health care should be offer to all patients, but practically, patients should receive optimum management with available resources. In the present study, the overall management results for patients grade I to III compare with those previously reported from developed countries with high medical development and new technology. We conclude, based on the data reported that selected patient population harboring intracranial aneurysms can be satisfactorily handled in nations with lower-technology, if a meticulous intraoperative technique is employed, even though sophisticated technology and equipments are not available.

Acknowledgments - We thank Marco Polo Baptista, M.D., for his assistance in computer analysis. 


\section{REFERENCES}

1. Adams HP, Kassell NF, Torner JC, Nibbelink DW, Sahs AL. Early management of aneurysmal subarahnoid hemorrhage: a report of the cooperative aneurysm study. J Neurosurg 1981;54:114-145.

2. Chyatte D, Fode NC, Sundt TM Jr. Early versus late intracranial aneurysm surgery in subarachnoid hemorrhage. J Neurosurg 1988;60:326-331.

3. Kassel NF, Torner JC, Jane JA, Adams HP, Kongable GL: The international cooperative study on the timing of aneurysm surgery: Part 2. Surgical results. J Neurosurg 1990;73:37-47.

4. Krupp W, Heienbrok W, Müke R.Management results attained by predominantly late surgery for intracranial aneurysms. Neurosurgery 1994;34:227-234.

5. Ljunggren B, Brand TL, Sundbarg G, Saveland H, Croquist S, Stridbeck H. Early management of aneurymal subrachnoid hemorrage. Neurosurgery 1982;11:412-418.

6. Miyaoka M, Sato K, Ishii S. A clinical study of the relationship of timing to outcome of surgery for ruptured cerebral neurysms. A retrospective analysis of 1622 cases. J Neurosurg 1992;79:373-378.

7. Nornes H, Wikeby P. Results of microsurgical management of intracranial aneurysms. J Neurosurg 1979;51:608-614.

8. Ohman J, Heiskanen O: Timing of operation for ruptured supratentorial aneurysms: a prospective randomized study. J Neurosurg 1989;70:55-60.

9. Sundt TM Jr, Kobayashi F, Fode N, Whisnant JP. Results and complications of surgical management of 805 intracranial aneurysm in 722 cases. J Neurosurg 1982;56:753-765.

10. Weir B, Aronyk K. Management mortality and the timing surgery for supratentorial aneurysms. J Neurosurg 1981;54:146-150.

11. Whisnant JP, Sacco SE, O'Fallon WM, Fode NC, Sundt TM Jr: Referral bias in aneurysmal subrachnoid hemorrage. J Neurosurg 1993;78:726-732.

12. Yasargil MG. Microsurgery applied in neurosurgery. Stuttgart: Georg Thieme Verlag, 1969:235-236pp.

13. Yasargil MG. Microneurosurgery; Vol 11. Stuttgart: Georg Thieme Verlag 1984:331-339.

14. Artiola I, Fortuny L, Prieto-Valente L. Long-term prognosis in surgically treated intracranial aneurysms. Part 2. Morbidity. J Neurosurg 1981;54:35-43.

15. Batjer H, Samson D. Intraoperative aneurysmal rupture: Incidence, outcome and suggestions for surgical management. Neurosurgery 1986;18:701-707.

16. Krayenbühl HA, Yasargil MG, Flamm ES, Tew JM Jr. Microsurgical treatment of intracranial saccular aneurysms. J Neurosurg 1972;37:678-686.

17. Le Roux PD, Elliott JP, Downey L, et al. Improved outcome after rupture of anterior circulation aneurysms: a retrospective 10-year review of 224 good-grade patients. J Neurosurg 1995;83:394-402.

18. Ljungren B, Saveland H, Brand L, Zygmunt S. Early operation and overall outcome in aneurysmal subarachnoid hemorrage. J Neurosurg 1985;62:547-551.

19. Post KD, Flamm ES, Goodgold A, Ransohoff J. Ruptured intracranial aneurysms: case morbidity and mortality. J Neurosurg 1977;46:290-295.

20. Shephard R, Ruptured cerebral aneurysms: early and late prognosis with surgical treatment. A personal series, 1958-1980. J Neurosurg 1983;59:6-15.

21. Hunt WE, Hess RM. Surgical risk as related to time of intervention in the repair of intracranial aneurysms. J Neurosurg 1968;28:14-20. 